\title{
THE REALITIES RELATED TO THE LIVING CONDITIONS OF UNISA'S UNDERGRADUATE STUDENTS RESIDING IN SUNNYSIDE, TSHWANE
}

\section{Assim Hashim Alpaslan}

\section{INTRODUCTION AND PROBLEM FORMULATION}

In its 2015 strategic plan: an agenda for transformation (2006:7), one of Unisa's mission statements is articulated as follows: "[to] address the needs of a diverse student profile by offering relevant student support, facilitated by appropriate information and communication technology". In an effort to make this mission statement a reality, a logical point of departure is to answer the following question: "What are the needs of students enrolled at Unisa?"

In attempting to answer this question, and as part of the motivation for her study focusing on "...the personal contexts of undergraduate students in social work at Unisa per se", Lintvelt (2008:2) notes pertaining to undergraduate social work students in particular that "...there is a lack of information on the undergraduate students and their personal contexts. Very little is known about their backgrounds, their physical environments, their financial situations and their conditions at home".

This observation seems to be true not only for the undergraduate social work students at Unisa, but for Unisa's undergraduate student population as a whole. A subsequent literature search on the proposed topic of investigation provided no information about the realities of the living conditions of Unisa's undergraduate students. Within the Department of Social Work at Unisa two research outputs were found that focused on issues relating to the living conditions of undergraduate social work students per se. One was the Lintvelt's master's dissertation (2008), and the other a journal article, in which Schenck (2009a) describes the socioeconomic realities of the social work students of the University of South Africa. Schenck's (2009a) article refers to Lintvelt's work and that of Wade (a doctoral student), who is currently investigating the traumatic experiences of social work students at Unisa in an attempt to highlight the importance of taking socioeconomic factors into consideration when the university plans its student support programmes. The fieldwork for both Lintvelt's and Wade's studies (according to Schenck, 2009a:303) consisted of questionnaires and focus group discussions facilitated by social work students during workshops at Unisa's regional offices in Pretoria, Cape Town, Johannesburg, Polokwane, Bloemfontein and Durban.

This dearth of knowledge about the realities related to the living conditions of Unisa's undergraduate students in general emerged as a central research problem. Coupled with this was an observation by the staff in the Department of Social Work that a large number of Unisa's undergraduate students seem to reside in Sunnyside, close to Unisa's main campus. This observation was confirmed during a personal interview with Mr Herman Visser, Senior Specialist: Information and Strategic Analysis, Department of Information and Strategic Analysis (DISA), Unisa, who noted that 4904 undergraduate and occasional students indicated their home addresses to be in the residential areas of Sunnyside.

Given the fact that there seems to be a lack of information about the realities related to the living conditions of Unisa's undergraduate students and the fact that a large number of these students live in Sunnyside, the Department of Social Work took the opportunity to undertake this research project with a view finding out more. According to feedback provided during an 
interview with Professor Rinie Schenck, the need for research into this topic was also mentioned by Professor Barney Pityana, Principal of Unisa, during his welcome address delivered at a workshop conducted on the proposed Centre for Applied Social Science on Poverty and the Family, held at Misty Hills on 16 January 2009 (Schenck, 2009b).

This research endeavour formed part of the research agenda of Unisa's Bright Site Service Project, which was recently established as a strategic project by the Department of Social Work with the support of the university and which was referred to by the Principal, Professor Pityana, in his address to mark the official opening of the 2009 academic year (Pityana, 2009:8-9). The mission of this service project was formulated at a strategic planning meeting held by the Department of Social Work on the $13^{\text {th }}$ of January 2009 as being to "integrate and capacitate the worlds of Unisa and communities by engaging in a mutually beneficial relationship through relevant services, learning opportunities, shared resources, research and policy." Furthermore, one of the objectives of this service project is "to provide accessible, holistic and comprehensive support services to Unisa and the broader community".

Given that Unisa's students, amongst others, form part of the residents of Sunnyside, the Department of Social Work sees them as part of the "consumers of services" of the aforementioned service project. This further served as impetus and motivation for undertaking this investigation into the realities and coping resources related to the living conditions of this resident group with a view to plan and/or put services in place aimed at addressing the needs of this consumer group.

\section{RESEARCH QUESTION AND GOAL}

One usually finds research questions, rather than hypotheses, written into the text of qualitative studies (Creswell, 1994:70). Research questions (relatively broadly formulated) identify the initial focus of the study and, together with the aims and objectives, become signposts for explaining the purpose of the study and beacons guiding the research endeavour (Fossey, Harvey, McDermott \& Davidson, 2002:723). Maree (2007:68-69) agrees and points to the fact that the research question specifies your area of interest and enables you to focus on what you will study. The question formulated at the outset of this study was as follows: "What are the realities related to the living conditions of Unisa's undergraduate students residing in Sunnyside, Tshwane?"

In guiding the process of answering this research question, the following goal was formulated: "To explore and describe the realities related to the living conditions of Unisa's undergraduate students residing in Sunnyside, Tshwane”.

\section{RESEARCH APPROACH AND METHODOLOGY}

In order to investigate the topic under discussion a qualitative research approach was followed. According to Fossey et al. (2002:717), "qualitative research is a broad umbrella term for research methodologies that explore, describe and explain persons' experiences, behaviours, interactions and social contexts without the use of statistical procedures or quantification". Creswell (2007:40) adds that qualitative research is conducted when a problem or issue needs to be explored and where researchers want to hear the voices of the marginalised and silenced.

Hence the qualitative paradigm appeared to be appropriate, because it helped me in my quest to obtain subjective, personal data about the realities experienced by Unisa's undergraduate students in relation to their living conditions in Sunnyside, Tshwane (realities which they view 
as "challenges"). This approach gave the undergraduate students, as self-knowing subjects, the opportunity to speak authoritatively about the situation being researched.

Within the qualitative approach I employed an explorative, descriptive and contextual research design or strategy of inquiry. Given the lack of information on this specific topic amongst the stated cohort and within the identified geographical context, I employed an explorative research design. Neuman (2000:21) explains that explorative research is undertaken when one aims to explore a new topic or issue. If the issue is new or has received little attention in the literature, one begins at the beginning, hence the term "exploratory research". In this case the descriptive design was used to provide a detailed description of what was explored (Neuman, 2000:21). The contextual design was also used, since I wanted to investigate a phenomenon in a specific context (i.e. the realities experienced in the contexts of Unisa's undergraduate students residing in Sunnyside, Tshwane, and the coping strategies they employ).

A non-probability sampling technique, purposive sampling, was employed, because I sought participants who were information-rich owing to their knowledge and ability to describe the phenomenon under study (Donalek \& Soldwisch, 2004:356). The fieldworkers (who were, amongst other things, responsible for the data collection) approached gatekeepers (i.e. fellow student social workers and fellow students) to put them in contact with participants who met the criteria for inclusion referred to later on in this article. Some of the fieldworkers also approached the students on campus on their way to the library and in the cafeteria to find out if they were undergraduate students residing in Sunnyside. If they were, the fieldworkers asked for a few moments of their time to inform them about the research and to determine their willingness to participate in the study. Some of the students approached in the end agreed to participate. Some of the individuals who participated in the study referred the fieldworkers to other participants who also agreed to participate in the study. Some of the participants even took the trouble to introduce some of the fieldworkers to the participants. As is usual in qualitative research, no sample size was determined at the outset of the study, but the principle of "saturation of data" determined the sample size. The fieldworkers continued with the collection of data from multiple participants until the themes emerging from the data became fully developed and repetitive (Donalek \& Soldwisch, 2004:356; Fossey et al., 2002:72). After conducting 24 semi-structured interviews, and transcribing the audio-recordings, I read through the transcriptions and then engaged in a discussion with the fieldworkers. All parties involved concluded that the data had reached a point of saturation and the process of data collection could therefore be concluded. Only participants who met the following criteria were included in the study:

- Participants who were currently registered as undergraduate students at Unisa;

- Participants who resided within the municipal boundaries of Sunnyside, Tshwane;

- Participants who were available and willing to participate in the study, in that they were fully aware of what the study entailed, and participated of their own free will.

Interviewing, focus groups and participant observation are common modes of qualitative data collection (Fossey et al., 2002:72). With reference to the "interview" as the mode of data collection used in this study, Babbie (2007:306) writes that: "a qualitative interview is essentially a conversation in which the interviewer establishes a general direction for the conversation and pursues specific topics raised by the [participant]. Ideally the [participant] does most of the talking". Semi-structured interviews were conducted by the fieldworkers. The 
content of the interviews was informed by an interview guide comprised of questions specifically formulated for the purpose of obtaining biographical data about the participants and a limited number of questions pertaining to the topic under investigation. Holloway and Wheeler (1996:55) and Kvale (1996:174) explain that in semi-structured or focused interviews the questions asked are those included in the interview guide (i.e. not in a schedule, as is the case in quantitative research), the focus being on the themes or issues to be covered. The following request and question were formulated specifically in view of the topic under investigation:

Request: Tell me about the realities related to your living conditions here in Sunnyside.

Question: What are the challenges you face in relation to the realities related to your living conditions in Sunnyside?

With the consent of the participants, all the interviews were audio-taped. On completion of the data-collection process, the fieldworkers transcribed the audio recordings word-for-word. Consequently, the process of data analysis commenced as a joint venture between the fieldworkers and me. Creswell (1994:153) contends that the researcher is engaged in several activities during qualitative data analysis. These include collecting the data, transcribing the interviews, sorting the data into categories, formatting the data into a coherent story or picture, and writing the qualitative text. The fieldworkers and I employed the eight steps provided by Tesch (in Creswell, 1994:155) to analyse the data systematically, by segmenting it into words or categories that subsequently formed the basis of the emerging story or picture.

For the purpose of data verification, I employed Guba's model of trustworthiness (as spelt out in Krefting, 1991:215-222), which identifies the following four criteria and strategies for ensuring and establishing trustworthiness, and which are therefore used to assess the qualitative research process undertaken.

- The first criterion addressed in establishing trustworthiness is that of truth value, that is, determining to what extent the findings are a true reflection of the "life-worlds" of the participants, as experienced and described by them. The strategy for establishing truth value is credibility. The particular actions taken to achieve credibility included triangulation (i.e. triangulation of data sources [i.e. interviewing multiple participants], and the triangulation of different investigators [i.e. the fieldworkers and the researcher] involved in this research project), peer examination (i.e. regular discussions and consultations between the fieldworkers, myself and other colleagues in the Department of Social Work), the interviewing techniques used by the fieldworkers, and the authority of the researcher overseeing the fieldwork process.

- The second criterion is applicability, or the degree to which findings can be applied to other contexts or settings and groups (i.e. generalisability). Transferability was the strategy employed to attain applicability. Two perspectives of applicability for qualitative research were delineated (Krefting, 1991:216). The first perspective holds that applicability is not seen as being relevant to qualitative research, because it proposes to describe experiences or phenomena which cannot be generalised to other experiences or phenomena (Krefting, 1991:216). The second perspective proposed by Guba in Krefting (1991:216), however, claims that fittingness is the criterion against which applicability of qualitative research can be assessed. If the findings of a study fit into contexts outside the study situation by means of similarity and goodness-of-fit between the two contexts, then transferability was achieved. In this study transferability was achieved by documenting "dense" descriptions of 
the research methodology, and by working contextually, so that procedures could be duplicated accurately.

- The third criterion in Guba's model (in Krefting, 1991:215-222) is termed consistency, which is concerned with the extent to which the replication of the study in a similar context or with similar informants will produce the same results. Dependability was the strategy used to ensure consistency. The actions that were taken to ensure that this study was reliable included peer examination of the research methodology, triangulation of data sources and investigators, a dense description of the research methodology, independent coding (i.e. the fieldworkers analysed each other's transcriptions independently and I also independently analysed the whole data set), and the implementation of a code-recode procedure (Krefting, 1991:216-217)).

- Neutrality is the fourth and final criterion, and refers to the extent to which the study's findings are free from bias. Lincoln and Guba in Krefting (1991:217) propose that neutrality in qualitative research should consider the neutrality of the data rather than that of the researcher, and thus suggested confirmability as the strategy for achieving neutrality. In this study triangulation (as explained above) was employed to achieve confirmability (Krefting, 1991:221-222).

\section{DISCUSSION OF FINDINGS}

The research findings presented in the next part of this paper resulted from the analysis of the 24 semi-structured interviews and a consensus discussion on the analysed data between me and the fieldworkers.

The discussion on the research findings will be presented in two sections:

- the geographical context where the fieldwork was conducted and the biographical profile of the participants; and

- a discussion on the theme (and sub-themes) that emerged from the process of data analysis and the consensus discussion. This discussion will be supported by narratives from the transcribed interviews and complemented by a literature control.

\section{THE GEOGRAPHICAL CONTEXT OF THE FIELDWORK AND RESEARCH PARTICIPANTS' PROFILE}

Sunnyside, as an inner-city suburb, was established in 1875 as a hamlet and incorporated into the municipal area in 1988 (Donaldson, Jürgens \& Bahr, 2003:23). Donaldson et al. (2003:11) note that Sunnyside has the highest percentage of residential units amongst the suburbs of the inner city and lies between Reitz Street and Park Road, Jameson and Kirkness Streets, Nelson Mandela Boulevard and Kotze and Jeppe Streets. Schenck (2008:2) delimits the borders of Sunnyside as follows: the city of Pretoria serves as the border on the western side of Sunnyside; the suburb of Arcadia is on its northern side and this hamlet consists mainly of flats and businesses; on the eastern side Sunnyside borders on Loftus Versfeld rugby stadium and the University of Pretoria - a more affluent residential area of Pretoria; the southern side of Sunnyside borders Muckleneuk (an affluent residential area) and the University of South Africa. Sunnyside is located centrally in terms of a number of easily accessible businesses, resources and training institutions. Sunnyside consists mainly of residential houses, highdensity areas with blocks of flats and the business centre (Schenck, 2008:2).

Table 1 below provides a biographical profile of the sample group. 
TABLE 1

BIOGRAPHICAL PROFILE OF SAMPLE GROUP

\begin{tabular}{|c|c|c|c|c|c|c|c|}
\hline $\begin{array}{l}\text { Participant } \\
\text { Code }\end{array}$ & Gender & $\begin{array}{l}\text { Age of the } \\
\text { participant }\end{array}$ & Race group & $\begin{array}{c}\text { Country/ Province } \\
\text { of origin }\end{array}$ & Marital Status & $\begin{array}{l}\text { Children, Yes/No? } \\
\text { If yes, how many }\end{array}$ & $\begin{array}{l}\text { Qualification currently } \\
\text { enrolled for at Unisa }\end{array}$ \\
\hline G1 & Female & 29 & Black $^{1}$ & Zimbabwe & Single & Yes: 2 & Information Technology \\
\hline $\mathrm{G} 2^{2}$ & Male & 57 & Black & Nigeria & $\begin{array}{l}\text { Divorced/ currently } \\
\text { single }\end{array}$ & Yes: 2 & Mathematics Literacy for FET \\
\hline G3 & Female & 39 & Black & Zimbabwe & Divorced & Yes: 1 & Community Development \\
\hline G4 & Female & 30 & Black & Angola & Single & No & Languages \\
\hline M1 & Female & 24 & Black & Soweto & Single & No & $\begin{array}{l}\text { BComm Financial } \\
\text { Management }\end{array}$ \\
\hline M2 & Male & 23 & Black & Nigeria & Single & No & Marketing \\
\hline M3 & Male & 18 & Black & Mpumalanga & Single & No & Mechanical Engineering \\
\hline M4 & Male & 21 & Black & Mpumalanga & Single & No & Mechanical Engineering \\
\hline T1 & Female & 20 & Black & Limpopo & Single & No & Risk Management \\
\hline T2 & Female & 22 & Black & East London & Single & No & Marketing \\
\hline T3 & Male & 26 & Black & Limpopo & Single & No & Human Resource Management \\
\hline $\mathrm{T} 4$ & Female & 23 & Black & Limpopo & $\begin{array}{l}\text { Married according to } \\
\text { tradition }\end{array}$ & Yes: 1 & International Diplomacy \\
\hline K1 & Male & 24 & Black & $\begin{array}{l}\text { Democratic Republic } \\
\text { of the Congo }\end{array}$ & Single & No & B Comm \\
\hline $\mathrm{K} 2$ & Female & 40 & Black & Limpopo & Single & Yes: 2 & Social Work \\
\hline K3 & Female & 29 & Black & Zambia & Single & No & Social Work \\
\hline $\mathrm{K} 4$ & Male & 24 & Black & Mpumalanga & Single & No & BSc \\
\hline F1 & Male & 22 & Black & Zambia & Single & No & BA Communication Studies \\
\hline $\mathrm{F} 2$ & Male & 36 & White & Gauteng & Single & No & Social Work \\
\hline F3 & Male & 36 & Black & Limpopo & Married & Yes: 2 & Development Studies \\
\hline $\mathrm{F} 4$ & Male & 20 & Black & Venda & Single & No & Chemical Engineering \\
\hline L1 & Female & 24 & Black & Limpopo & Single & No & Social Work \\
\hline L2 & Female & 25 & Black & Limpopo & Single & No & Statistics \\
\hline L3 & Female & 21 & Black & Limpopo & Single & No & Public Relations \\
\hline $\mathrm{L} 4$ & Female & 26 & Black & Limpopo & Single & No & Safety Management \\
\hline
\end{tabular}

\footnotetext{
${ }^{1}$ In relation to the race of the participants, all the black participants were from Africa (i.e. Blacks).

${ }^{2}$ This participant is a qualified chemical pathologist.
} 
The above Table shows that the majority of the participants in the sample were black Africans. This phenomenon typifies Unisa's student profile because, according to Unisa's HEMIS figures for 2008 on Unisa's Intranet, $64.6 \%$ of the undergraduate and occasional students registered at Unisa were from the Black population group. With reference to the participants' countries and provinces of origin, it became clear that eight participants had migrated from elsewhere in Africa to South Africa and this trend is confirmed by figures on Unisa's Intranet, which point to the fact that in 200820097 individuals from Africa were enrolled as undergraduate or occasional students at Unisa (Unisa's HEMIS Figures for 2008). Of the remaining 16 participants, 12 were originally from the Limpopo province.

From the interviews conducted, the participants put forward the following motivations for relocating to stay in Sunnyside:

- The majority of the participants moved to Sunnyside to be closer to the university. In confirmation of this sub-theme, the following storylines are provided:

I [am] studying at Unisa and this place is the closest to school [i.e. Unisa], so I decided to come and stay in Sunnyside.

I moved to Sunnyside because Unisa's library is near where I stay, it is only a few kilometres away from where I stay. That's the reason I moved to Sunnyside.

Because in Nelspruit there is no library like here. Because I am a Unisa student and because in Sunnyside there are libraries, but if I go to school, I use Sunnyside, Thutong, if it is late ... the facilities are better here in Sunnyside.

- Some participants decided to stay in Sunnyside because this is where foreigners seem to congregate and they feel safe amongst fellow foreigners. This was deduced from the following quotations:

I ... found it very convenient to reside in Sunnyside because it's mostly occupied by foreign people and I find it very convenient to live among the foreign people other than the South Africans. I am afraid of the xenophobic attacks and I feel very insecure to mix with these South African people, especially the men. So here in Sunnyside since it's a place where most foreigner people are staying, I find it convenient and comfortable because I can share with them more freely, unlike the South African community. The other thing is accommodation is easily accessible at an affordable rent.

In the first instance when I came to Pretoria I wanted to study IT and the school was in Hatfield... I wanted a place that was close enough to Hatfield where I could get to school easily. Not being too expensive either and at that time the only place where I could get suitable [accommodation] (in terms of funds and proximate to my school) was Sunnyside. Hence, I settled in Sunnyside. [Secondly]..., I wanted a situation where I could be amongst most foreigners rather than living on my own in the midst of South African communities because ... practically ... within that short space of time, I have experienced there [is] no reception of South Africans to what they call "visitors" or "strangers". The only way I could feel safe was in the midst of foreign people. And I found a lot of them here in Sunnyside - that was why I came here. Hence Sunnyside has become a place of residence for me.

These participant's reference to "no reception of South Africans to what they call 'visitors' or "strangers"" is confirmed in a 2006 study conducted by a South African Migration Project cited 
by McConnell (2009:34), which revealed that "South African nationals are particularly intolerant of non-nationals, and especially African non-nationals".

\section{REALITIES EXPERIENCED BY THE PARTICIPANTS' RELATED TO THEIR LIVING CONDITIONS IN SUNNYSIDE: A THEMATIC DISCUSSION}

The responses from the participants produced one major theme: Realities experienced by the participants' related to their living conditions in Sunnyside.

These realities were divided into the following sub-themes: realities experienced in relation to overcrowding; being the victim of and/or witness to crime; exposure to noise; exposure to xenophobia; exposure to high rentals, exploitation by landlords (i.e. high rentals charged for apartments) and lack of service delivery by landlords and letting agencies; financial difficulties; constant relocation whilst staying in Sunnyside, and being confronted with the realities of drugs, beggars, prostitution and street children. Other realities experienced were the proximity to amenities; the readily availability of public transport; and the fact that Sunnyside provides connection and a place to belong.

This theme with its accompanying sub-themes and categories (where applicable) are discussed in the remainder of this article and the former will be subjected to a literature control.

While the participants were speaking about the realities experienced in terms of their living conditions, it became clear that the majority of these realities were expressed in such a way that they could be labelled as "challenges" and "obstacles". Only a few of these realities could be grouped under the label of "benefits". In the next section of this article I shall present the realities experienced by participants' as a result of living conditions in Sunnyside.

- Sub-theme: overcrowding as a reality experienced by participants in relation to their living conditions

In confirmation of this sub-theme I quote the following remarks made by some of the participants:

[Sunnyside is] "overpopulated... [It's like a] "squatter camp ... you don't know if it is a squatter camp or city [referring to all the people selling all over the streets]." Later on she mentioned: "you find more than 10 people in one flat ... it is unfair to me. I am staying with my two children and we are not using so much water, but at the end of the day we must pay ... for the 10 people living [there].

... [I stay] in a two and a half [bedroom flat] but the landlady [note that this is not the landlady, but rather the person letting from the flat owner] divided the sitting room into two rooms so there are now four and a half rooms... I live in half, [in another, a] guy and his girlfriend. [They] recently had a baby. Other room two people - another guy with girlfriend. Other room is empty; landlady is looking for someone to move in. [The] body corporate of building pressure as [they] don't want rooms. But she wants. Everyone wants money.

Schrire (1990:162) states that, judging by international standards, more than 1.5 persons living in a room constitutes overcrowding and, judging from the remarks above, the participants certainly seem to be faced with this reality. One participant gave the reason for the overcrowded living conditions in Sunnyside: "The problem is that things are expensive. Most of my friends are sharing with their friends. You find that they are six in one room. This is because the flats are expensive and there is no money." 
152

The participants' overcrowded living conditions compromise hygienic living conditions. One participant articulated this as follows: "You can't share with seven people. Not hygienic. Not everyone is clean. Not on the same level. You find people misuse the public places. Make place untidy ... bathroom unclean. [I] feel sorry for the girls living with the guys." This participant later on spoke about how he regularly had to clean the kitchen left in a mess by fellow tenants before he could cook for himself. He got fed up with this and turned to buying "takeaways", which placed an "extra burden on his budget".

The overcrowding experienced by the participants also resulted in some of them experiencing $a$ lack of privacy. The following two storylines confirm this: "people do not respect another person's space in the flats", and "you live with people all the time. It has an effect on me". Leacock (1971:253) supports the feelings demonstrated in these remarks when he states that "the lack of privacy is entirely a function of crowdedness".

Another issue feeding into this phenomenon of the overcrowding experienced was "visitors. People welcome visitors". These visitors not only make further inroads into the participants' privacy, but also raise safety concerns. One participant said: "See how many people in flat. [It] raises amount of security. You don't know people, the security. You can't go to the bathroom and leave room open. You don't know who is going to walk in. You don't know the visitors who have to come and see other people. Might get something from you". Another remarked: "People do not respect another person's space in the flats... none of your things are safe. Even though you trust your flatmates, you do not trust them completely. Once... someone opened up a Woolworths account under my name. I cannot leave anything around. I have to hide most of my things. Something I have to hide very well is my ID. People steal other people's IDs in the flats and sell them. I can of course never leave money lying around. My phone is also something I have to keep with me at all times".

The participants found it difficult to share limited living space not only with flatmates, but with visitors - "You see in our culture [i.e. the African culture] people do not phone to say that they will come to visit. They just arrive and invite themselves to stay over". As a result of this and because of the lack of space "you always have to think going wherever". This lack of living space endangers social harmony (Murphy, 1997:205) and the participant quoted above stated that if she raises her concerns about her flatmate's friends, the flatmate always says: "I also pay rent; my friends can stay if they want".

While most of the participants experienced their living spaces as being overcrowded, a few participants were fortunate enough not to be living in such conditions. The following two storylines testify to this: "Yes, I am fortunate enough not to have to share", and "I ... moved into the one bedroom flat ... a big improvement... I have my own kitchen and bathroom..."

- Sub-theme: crime as a reality experienced by participants in relation to their living conditions

All the participants referred to the fact that Sunnyside was a crime-ridden area. In supporting this, an article by Fourie in the Beeld of 25 September 2008 quotes crime statistics released earlier that week, which showed that house robberies in Sunnyside had escalated by $65 \%$ from 63 incidences in 2007-2008 to 104 in 2008-2009. The number of murders committed went up from five in 2007-2008 to 11 in 2008-2009 - an increase of 83.3\%. Car hijackings increased from 66 in 2007-2008 to 112 in 2008-2009, which was an increase of 69.9\%.

Contrary to the participants' view that Sunnyside is a dangerous place to live in, Inspector Ramaloko (quoted by Du Plessis, 2006:4) stated in the Pretoria News of 23 May 2006 that this 
was not the case and that "crime is under control, even though the area is not crime free". (It must be noted that this comment was made in the period before 2008-2009). Residents (quoted in this newspaper article) disagreed and mentioned that crime in Sunnyside is an everyday occurrence and that Sunnyside was a dangerous place. Many residents say that they have to lock their doors at night and remarked that one can get shot for a phone, a car or household goods. Esselen Street was referred to as "hell", because there are a number of clubs in this street, resulting in alcohol abuse and muggings (Du Plessis, 2006:4).

The following accounts underscore the fact that crime is a concern and that some of the participants had nearly been victims of crime or had in fact been victims of crime:

[Crime] is actually a concern for all the students. Most people on their way from school [referring to Unisa] get mugged and they target students. They face that same problem to school. Then they take your whole bag and they only look for money and phones, dumping your entire bag. So you lose the entire bag.

...there was another guy, he was black, he was following me, and he took the phone, he just brings the knife and he took the phone.

Another problem living in Sunnyside is the high levels of crime. Not so long ago a few guys came to knock on our door. They said they were here to replace the geyser. We were not aware that our geyser was broken, but they had their story nicely planned out. When I turned around to ask one of the others if they knew anything about it, they just forced their way in. They demanded that we hand over all our phones and money. This happened a previous time as well when other guys said they are here to see someone. My flatmate who answered the door told them they must have the wrong flat because that person does not live here. Again they forced their way in and demanded the phones and money. There is not anything else they can take because we have very little.

Most of the participants described incidents to the fieldworkers about friends who were victims of crime and violence. They stated:

I have not been mugged but friends walking with me have been. It goes on every day in Sunnyside.

They are breaking in the flats. If you are inside the flat and you don't lock your door, some boys will come. They will gunpoint you and take everything in the house, so it is not safe ...my friend had that experience. They broke into his flat and stole his computer and cell phone and they took his money.

The one girl I lived with had a terrible boyfriend. He would just arrive at any time. He used to beat her terribly in front of the rest of us. I would try to stop him but he would beat me too. So one day, all five of us decided when he arrives again we will all be ready for him. When he got there we all just jumped him. The neighbours heard the commotion but did not stop us. In the end they were helping to beat this guy. He never returned after that day.

While this storyline refers to how the participant and her friends came to a fellow flatmate's rescue, the following account refers to the apathy of fellow flat dwellers when a person becomes a victim of crime: "Well these guys always manage to get into the building. They just tell the security they going to flat 34 to see so and so. This person does not even exist. The security let them in. When you scream or shout, when they are in your flat, no one will come to help. People are so used to boyfriends hitting girlfriends; they just don't want to get involved. 
Even if your door is open the whole day after someone has broken in, no one will think anything of it. They will just assume you are at the washing line or left the door open for some reason."

In concurring with the aforementioned accounts by the participants, Schenck (2008:4) found that each person the students talked to during their community awareness walk in Sunnyside mentioned "crime" as one of the biggest problems in the area. The most frequent crimes committed were car thefts, hijackings, smash and grabs, and stealing cell phones. The people regarded the nights as the most dangerous time.

- Sub-theme: noise as a reality experienced by participants in relation to their living conditions

Passchier-Vermeer and Passchier (2000:123) state that noise exposure is on the increase, especially in the general living environment, both in industrialised nations and in developing countries. Noise exposure can lead to hearing impairment, hypertension and ischemic heart disease, annoyance, sleep disturbance and decreased school performance. Noise exposure was another reality (and challenge) experienced by the majority of the participants and proved to be an element beyond their control. They referred to this reality as follows:

...noise, even at night it is more like it is during the day. It is always - screaming, the music, the cars, all the time!

...over weekends ... there are sirens from ambulances and police up and down ... there are all these churches ... there are a lot of foreign churches in the area and they make a lot of noise on Sunday mornings.

But in terms of studies, a lot of noise here...A lot of noise in Sunnyside ... it is too much noise, especially on weekends...

One participant perceived South Africans as the people who made the most noise and stated that: "parties can go on throughout the night weekends; basically these parties are from the South Africans community life style. It's very rare to hear foreigners having a party and even if they do, they don't play music until the following morning, but with South Africans you can hear them play loud music until the following morning and sometimes when I come from my part-time jobs and I want to concentrate on my studies I find it very inconveniencing”.

While the majority of the participants spoke about the noise in Sunnyside and in their blocks of flats, three stated that they stay in quiet blocks of flats and remarked: "... this block of flats only took professional people ... it's very quiet”; “... no, where I am staying - it's a place that is quiet", and "...Some flats have caretakers, some none, who will allow you to make noise... For me, where I am, the caretaker does not allow us to make noise... Also the noise from outside does not disturb [me] as clubs are not nearby".

- Sub-theme: xenophobia as a reality experienced by participants in relation to their living conditions

Xenophobia can be described as a negative attitude or antipathy towards foreigners, and includes a dislike, hatred or a fear of foreigners (Hook \& Eagle, 2002:170). Kollapan (in Hook \& Eagle, 2002:171) warns that xenophobia cannot be separated from violence and physical abuse. The author is of the view that the term "xenophobia" needs to be redefined in the dictionary to incorporate practice, since xenophobia is not just an attitude, but an activity. According to Hook and Eagle (2002:182), exclusion, alienation and hostility operate in a complex, ongoing spiral across the line of nationality (i.e. between South Africans and 
foreigners, particularly African foreigners). Xenophobia makes "foreigners feel foreign." This effect, in turn, alienates and excludes foreigners further from South African society. During their awareness walk in Sunnyside, the third-level student social workers found the locals to be negative towards the foreigners, because they believe that these people bring drugs into Sunnyside and take away jobs and business opportunities from local people (Schenck, 2008:5).

The participants, in particular some of the foreign nationals, made reference to the reality of xenophobia in Sunnyside and one participant expressed this as follows: "there is race, racial issues like this xenophobic attack that happened sometime ago, we are afraid that it will come to us too and sometimes you know when people know that you are a foreigner they don't treat you like as a local person, you will find that especially with students". This experience, according to one participant, caused foreign students to be fearful and hesitant about establishing relationships with the locals: “... here in South Africa I wouldn't say I have associated much with any cultural group for the fear of xenophobic approach by people around here. So I need to be very careful. So I have always kept to myself in most cases".

Finding employment in South Africa as a foreigner seems to be an obstacle. One participant said: "It is not easy for me to find a piece work around because most people don't want to employ foreigners ... maybe the xenophobia."

One participant described how foreign nationals become victims of xenophobia, and stated: "I am sorry to say because in South Africa it's not easy to be involved with groups like the Zulu. They call us 'Makwerekwere' and they like to beat us. So we cannot be involved with them."

While some participants referred to the reality of xenophobia in Sunnyside, two participants viewed Sunnyside as a shelter for foreigners where they can be safe against xenophobic attacks: "I also found it very convenient to reside in Sunnyside because it's mostly occupied by foreign people and I find it very convenient to live among the foreign people other than the South Africans. I am afraid of the xenophobic attack and I feel very insecure to mix with these South African people especially the men", and "... the xenophobic violence that has been around ... it hasn't come to Sunnyside, it has never done, as it [i.e. Sunnyside] is a place offoreigners".

- Sub-theme: exploitation by landlords (i.e. high rentals charged for apartments) and the attitude of landlords and letting agencies towards tenants, and lack of service delivery by landlords and letting agencies

While Blignaut and De Wit (2004:436) claim that Sunnyside is characterised by low- to middle-income apartment buildings, Van der Merwe (1984:191) notes that "landlords" (i.e. the owners themselves, or people who control on behalf the owners) in some instances rent their residential units with the aim of maximising their rental income (i.e. profit making) and, as a result, discriminate against particular groups. Some of the participants made reference to being exploited and having to pay high rental amounts for their apartments in Sunnyside.

The only problem is the expensive rent. We are paying $R 4000$ without electricity. The rent in Sunnyside is very high.

...we pay quite a lot [referring to rent] ... [the rents in Sunnyside are high], ja, that is why in some of the flats we find more than one family or a lot of people, eight to nine. Each one has to pay.

In confirmation of this, Drakakis-Smith (1992:77) notes that some landlords who own multiple dwellings resort to rack-renting practices. 
While the aforementioned storylines bear testimony to the fact that the rental amounts charged for apartments in Sunnyside are high, a few participants seemed happy with the amount of rent they had to pay:

I am happy with the rates. It is not too expensive. Well I can say it is affordable.

...the other thing is accommodation is easily accessible at an affordable rent.

Apart from the high rental amounts charged for apartments in Sunnyside, another reality referred to by the participants (in some instances as a challenge) was the landlord and letting agents' attitude towards tenants. The participants experienced that the landlords and letting agents: (1) are just chasing money and they do not have the tenants' interests at heart; (2) they have no regard for the participants' safety; (3) they do not attend to requests for maintenance work; and (4) they seem to be very prescriptive in terms of who should be renting their apartments.

Category 1: The landlords and letting agents are just chasing money and they do not have the tenants' interests at heart. Referring to this category, the participants said:

...they [referring to the landlords and letting agencies] are only interested in getting the rent and nothing else.

...people in Sunnyside make business of flats. One would get a flat and then put people in different rooms and then charge more than he's paying. So he ends up paying nothing and you end up by paying everything.

Charlesworth (2005:156) confirms this finding and claims that many landlords "milk" their properties and then abandon them.

Category 2: Landlords and letting agents have no regard for the participants' safety. The following storyline refers to this:

As I told you, people move around a lot. This happens especially when they owe a lot of rent. When these people move they keep their keys. So it could be that ten other people have keys to the flat you find yourself living in. The rental agencies do not bother to get the keys back. Because these people disappear because of outstanding rent, it is not like they will go and give it back to the agency... When you ask the agency if they will put in new locks, they normally say "No, it is too expensive..." They do not take into consideration the safety of us who are renting from them and paying our rent every month.

Category 3: Landlords and letting agents do not attend to requests for maintenance work to be done in apartments.

It was the foreign nationals in particular who referred to this reality because, in their experience, they are treated differently from South African tenants by both landlords and letting agencies. They stated:

Let me address the issue of the flat where I live. For instance, I know that I have written a couple of letters to the agency, because when I moved in it was in a dilapidated state and I moved in with the understanding that things like repairs will be done when I am in there, but to date nothing has been done. The same things go when I go to pay my rent. There you will see that the way they treat you will show signs of xenophobia. Nobody has bothered to address my issue. 
There is sometimes where you find a lift stuck, [but] you know the process to sort the problem out is not something that can be done overnight... Just because the lift isn't working you can't go and violate the manager. People are different, when you tell people you have a problem they seem if you try to be superior... you are to undermine his managerial authority - whereas somebody can just see its failing. You keep quieteven if you don't get a reliable service. [You] can't phone CitiProp [letting agent] and tell them you have a problem ... then you need an ID [i.e. referring to the fact that only the person who is the lawful tenant can do it].

The following storyline relates to the fact that, in some instances, people who are staying in the flats are not the tenants who rented the apartment, so they cannot request the agencies to do maintenance work: "...when coming to maintenance you have to consult [i.e. the letting agencies] because people just say: 'they [referring to the letting agencies] don't take care of us, they don't do this and this for us'. They don't consult the agency to tell them that something is wrong, because some students in Sunnyside have hired flat not with their names so they can't complain. If you move into a flat and the bill is not in your name, you can't complain".

In confirmation of the above, Simon (in De Wet \& Fox, 2001:295) states that, in order for tenants to meet high rentals, and to help relatives or friends without accommodation or who face the long, expensive commute from the townships, tenants begin taking in sub-tenants. Multiple occupancy becomes common, services and infrastructure become overloaded and landlords cut back on, or cease to undertake, any form of maintenance.

Category 4: Landlords and letting agents seem to be very prescriptive in terms of who should be renting their apartments.

... when I applied to stay there the caretaker said to me they did not allow Blacks here ... if you have black friends don't bring them into here. ${ }^{3}$

- Sub-theme: financial difficulties as a reality experienced by participants in relation to their living conditions

In support of this sub-theme one participant stated that "the one obstacle which has affected me a number of times, there is no clinic in Sunnyside. There are only doctors. Doctors are very expensive. I had to pay R220 for an appointment. Then you still need to get your medicine. So most of the time if you get really sick, you just leave it until you get better. The last time I was really ill. I had to go to the doctor twice. That was very difficult. It was a lot of money and I did not have money for food".

Participants also referred to financial difficulties experienced in relation to the fact that fellow tenants do not pay their share of the rent, water and electricity and then they suffer as a result. They expressed this state of affairs as follows:

...it is difficult when it comes to dividing rent and electricity... we were actually two families staying ... in this flat. One day we got to the flat and a locksmith was there. He was instructed by the agency to bolt the flat. There were large amounts outstanding. We only became aware then that two of our flatmates were never paying their rent. We had to pay the R500 for the locksmith who bolted the flat. We then had to provide our deposit slips. Although those two were held responsible for the outstanding rent, we were all

\footnotetext{
${ }^{3}$ Prior 1994, Sunnyside as hamlet of the city of Tshwane was primarily inhabited by White South Africans.
} 
liable for the interest payable on the outstanding amount. This was difficult. So just like that I was out on the street.

... paying for electricity bills. Recently they cut our electricity because we didn't pay. Some people were just promising. I cannot pay for them and they cannot pay for me. So when one fails to pay it becomes a debt and it accumulates ... and they cut our electricity.

Another participant informed the fieldworker that he has financial concerns because his work contract has expired. However, his wife is working and he remarked that "you will have to cut that expenditure due to the challenges and circumstances".

While these storylines refer to financial difficulties experienced, the following remark by one participant illustrates that he is able to meet his financial needs: "My rent is R2000, electricity R150, DSTV R200, laundry R120 to R150 and food is R1000, if not more, all costs which I can cover with the salary I earn as an auxiliary social worker."

- Sub-theme: being confronted with the realities of drug dealers, drug and alcohol abuse, beggars, prostitution and street children

This sub-theme originated as a result of the following remarks made by participants:

...then the drugs there are people down here [i.e. referring to entrance of the flat] selling all the time ... I am mostly just aware of them... Most of the drug dealers are very friendly, so then I am just friendly back.

Leggett (2001:10, 130) states that "people who make and sell illegal drugs are not bound by any rules" and the "the war on drugs became an end in itself, an industry providing thousands of jobs". (The fieldworker who interviewed this participant quoted above was approached by drug dealers upon entering and exiting the flat where he conducted the interview with the participant quoted above. The one remarked: "Whites only come here to get drugs. Why are you here?")

Sunnyside is only place that is corrupt, too much, because wherever you go, you get these people called "Nigerians" they sell drugs. During the night you don't even have enough time to stand or stop anywhere. [If you do] at the corner, somebody will come to you and ask you if you have the stuff. If you say, "I don't have the stuff", they will be asking you if you are... the police or somebody without this drug dealers.

...I have friends who are drinking alcohol every day. They are asking me to join them to drink alcohol. Another big problem in Sunnyside is drugs. People use drugs...There are students who are using drugs ... they are [easily available], because most of the foreigners are selling drugs.

I have seen prostitutes around the place. The thing is most of these girls when they come here they get introduced to drugs. I won't say its foreigners but most are foreigners who are selling drugs. So they provide them [i.e. the girls] with these drugs. After some time they don't give them drugs they have to be prostitutes so that they can finance the lifestyle.

They [referring to prostitutes] are everywhere. There is no decency to it, and sometimes when you tell people that you are staying in Sunnyside they think you are a prostitute.

Many of my friends have turned to prostitution... It is not that they stand on street corners. When we go to the shops to buy food or to a takeaway place, they will start 
talking to men. Every time they find someone who is willing to pay. I call them "Mr Airtime" or "Mr Clothing account"... They do not bring these men to our flat, but they go with them to their places or in their cars. This is what they are doing to get the money to pay for what they need.

Walker, Reid and Cornell (2004:23) confirm this scenario by postulating that prostitution is a desperate way of trying to survive and, for others, a method of acquiring commodities.

...beggars and street children and everywhere you come out of the shops always there are beggars asking for money.

...there are lots of street kids... In 2006 there were street kids, but not as they are now.

Schenck (2008:5) reported that students who undertook the community walk in Sunnyside also came across street children who lived under a bridge with other homeless people.

The discussion of the findings thus far has highlighted the realities experienced by the participants in relation to their living conditions which (as stated earlier) could be labelled as "challenges" and "obstacles". In the next section of this article I shall discuss a few realities that can be labelled as "benefits" of living in Sunnyside.

- Sub-theme: proximity to amenities

Wasserman and Faust (1994:203) define proximity as closeness that focuses on the distance to rather than from individuals, places, services etc. The participants also defined proximity in relation to Sunnyside's closeness to certain amenities and groups.

The following storylines support this choice of a sub-theme:

...Sunnyside [is] close to everything...church, friends and school is here... cell group is here...

...the reason why I chose to stay here is because it's close to where I am working and Sunnyside campus is down the road. Everything is within walking distance. All the shops and everything are here in walking distance so that makes it convenient for me. I don't have my own transport.

- Sub-theme: the ready availability of public transport

The ready availability of public transport was another "benefit" of staying in Sunnyside.

We came back to Sunnyside for convenience, because I just have to go up the street to get a bus or a taxi rank to get to the work and it works out much cheaper... I do not have to think "Oh, where will I get a taxi?"

...going to places like Menlyn, yes, I would use a taxi. There are buses but I don't know the bus schedules, and I don't want to stand on a corner waiting for a bus, taxis are very convenient.

- Sub-theme: Sunnyside provides for connectedness and a place to belong

Zimba (in Keller, Pootinga \& Schölmeric 2002:90) quotes Brislin, who postulates that "culture confers group membership on people. This comes about through an internalization of identifiable and particular customs and traditions, values, beliefs, practices and ways of reasoning about human life and ways of being such as those interdependence, relatedness, separateness, independence, "communalism' and connectedness". Through associating with a 
specific culture, a sense of belonging is promoted which results in a feeling of connectedness. The following comments by the participants confirm this:

I moved to the flat since the start of this year... I just had to move for myself, I wanted to live with family ... because sometimes you get lonely here in Sunnyside or you have problems and you need someone to go to..."

This storyline illustrates the participant's need to feel connected and to belong.

I stay basically in the heartbeat of Sunnyside ... we call it "Hlanganani" a place where everybody meets.

It is in "the place where everybody meets" (i.e. Sunnyside) that participants find a sense of connectedness.

Then the interaction [i.e. connectedness], that's why it's convenient for students to live here.

A participant staying with a friend and the landlord and his family also experience the "connectedness" referred to above when he stated: "we are living as a family... it feels good, like Nelspruit [home] and I don't miss it so much".

Sunnyside seemed to provide foreigners with a place to belong and connect, as illustrated by the following remarks:

I wanted a situation where I could be amongst most foreigners than living on my own in the midst of South African communities because ... practically ... within that short space of time, I have experienced there [is] no reception of South Africans to what they call "visitors" or "strangers". The only way I could feel safe was in the midst of foreign people. And I found a lot of them here in Sunnyside that was why I came here. Hence, Sunnyside has become a place of residence for me.

So here in Sunnyside since it's a place where most foreigner people are staying, I [a foreigner too] find it convenient and comfortable because I can share with them more freely unlike the South African community, and the other thing is accommodation is easily accessible at an affordable rent. Those are some of the things that made me come here.

It was also interesting how the similarities or connectedness in terms of languages emerged as the basis for connectedness among the participants. It was highlighted by one participant that "In Zimbabwe it's like I associate with Ndebeles more. Yes. Here in South Africa I find it easier to associate with Zulus. Yes, I can speak Ndebele which is more like Zulu."

\section{CONCLUSIONS AND RECOMMENDATIONS PERTAINING TO FURTHER AND FUTURE RESEARCH}

The above research findings present the realities of a sample of Unisa's undergraduate students experienced in relation to their living conditions in Sunnyside, Tshwane. Based on the research findings and the literature verification, several interpretations and conclusions can be offered.

Undergraduate students experienced diverse and complex realities in relation to their living conditions in Sunnyside and the majority of these can also be classified as "challenges" or "obstacles". Their living conditions are extremely noisy, overcrowded, unsafe, expensive, unstable (because of constant relocation) and they are exploited by landlords and letting agents. Furthermore, they are confronted with social realities such as xenophobia, crime and violence, 
drugs, prostitution, street children and beggars. Apart from the realities referred to above (which can be labelled as "challenges"), I concluded that the following are benefits experienced by the participants in relation to their living conditions in Sunnyside: the proximity to amenities; the ready availability of public transport, and the fact that Sunnyside gives them a sense of connectedness and a place to belong.

\section{Recommendations for future research}

- That this research project be replicated using a sample of white, coloured and Indian undergraduate students residing in the area investigated (since only one participant from the white population was included in the sample and none from the coloured and Indian population groups);

- That a research project be undertaken to explore the realities and coping resources related to the living conditions of Unisa's postgraduate students who reside in Sunnyside;

- That this research project be replicated in the other cities where Unisa has regional offices (i.e. Cape Town, Johannesburg, Polokwane, Bloemfontein and Durban);

- That a research project be undertaken to identify (i.e. explore and describe) the nature of support needed by Unisa's undergraduate students residing in Sunnyside and their perceptions of Unisa's role in addressing these needs.

\section{A final remark}

The following remark, made by a participant, aptly encapsulates the realities and coping resources experienced by Unisa's undergraduate students residing in Sunnyside:

Sunnyside is a world of realities. Many people leave their homes with high visions but Sunnyside deviates, changes their focus. Nobody can claim ownership of Sunnyside. Foreigners, locals everyone is around. Fun, drugs, prostitution - anything that can derail a student coming from matric... naïve, without support from parents. You are your own father, your own mother. You have to stand strong. The challenge is very much great. But one will need to fight to keep their goals, to keep strong. It is a battle. Again for those doing Unisa, a major challenge. You have to study on your own, you have to discipline your life. They don't teach you how to discipline at school or home. When I come in Sunnyside, I am alone. I have to do it. Only the strong survive... It does feel like home... You've known the place. You've learnt in this context. Life is somehow fine. You've got nothing to remind you of home. Your eyes are shaped to see South Africa. The people make it hard for you - xenophobia, psychological rejection and all that. That's how life is... you go to one community, the other rejects you. When you approach a community and they speaking their language which you don't understand and they don't make efforts to help you understand, they are saying: "we are we" and "you are you"... You just have to find a way to enter or to live like that ... especially as a foreign person, a student, a young person because there are still desires of the Young. You wanna have fun. You don't want to let your life go in university. The fun part of life cos after university is work, so you want to have fun. At same time you have to focus, so that's a challenge.

\section{REFERENCES}

BABBIE. E. 2007. The practice of social research $\left(11^{\text {th }}\right.$ ed). Belmont, Calif.: Wadsworth.

BLIGNAUT, J.N. \& DE WIT, M.P. 2004. Sustainable options. Cape Town: Juta \& Co. 
162

CHARLESWORTH, E. 2005. City edge: case studies in contemporary urbanism. London: Elsevier.

CRESWELL, J.W. 1994. Research design: qualitative and quantitative approaches. Thousand Oaks, Calif.: Sage Publications.

CRESWELL, J.W. 2007. Qualitative inquiry and research design $\left(2^{\text {nd }} \mathrm{ed}\right)$. Thousand Oaks, Calif.: Sage Publications.

DONALEK, J.G. \& SOLDWISCH, S. 2004. Demystifying nursing research: an introduction to qualitative research methods. Urologic Nursing, 24(4):354-356.

DONALDSON, R., JÜRGENS, U. \& BAHR, J. 2003. Inner-city change in Pretoria: social and spatial trends. Acta Academia Supplementum, 1:1-33.

DRAKAKIS-SMITH, D.W. 1992. Urban and regional change in Southern Africa. London: Routledge.

DU PLESSIS, J. 2006. The Sunnyside of crime. Pretoria News, 23 May: 4.

FOSSEY, E., HARVEY, C., McDERMOTT, F. \& DAVIDSON, L. 2002. Understanding and evaluating qualitative research. Australian and New Zealand Journal of Psychiatry, 36:717732.

FOURIE, H. 2009. Huisroof op en moord af. Bykans 2000 Pta-gesinne slagoffers van rowers in hul wonings. Beeld, 25 September: 6.

HOLLOWAY, I. \& WHEELER, S. 1996. Qualitative research for nurses. London, Great Britain: MPG.

HOOK, D. \& EAGLE, G. 2002. Psychopathology and social prejudice. Cape Town: University Press.

KREFTING, L. 1991. Rigor in qualitative research: the assessment of trustworthiness. The American Journal of Occupational Therapy, 45(03):214-222.

KVALE, S. 1996. Interviews: an introduction to qualitative research interviewing. Thousand Oaks, Calif.: Sage Publications.

LEACOCK, E.B. 1971. The culture of poverty: a critique. New York: Simon \& Schuster.

LEGGETT, T. 2001. Rainbow vice: the drugs and sex industries in the new South Africa. London: Zed Books.

LINTVELT, RA. 2008. The personal contexts of undergraduate students in social work at Unisa. Pretoria: Unisa. (Unpublished MA Dissertation)

MAREE, K. 2007. First steps in research. Pretoria: Van Schaik Publishers.

McCONNELL, C. 2009. Migration and xenophobia in South Africa. Conflict Trends, 1:34-40. MURPHY, D.T. 1997. The heroic earth. Kent, Ohio: University Press.

NEUMAN, L.W. 2000. Social research methods: qualitative and quantitative approaches $\left(4^{\text {th }}\right.$ ed). London: Allyn \& Bacon.

PITYANA, B. 2009. Principal's address to mark the official opening of the academic year 2009. Pretoria: Unisa. 
PASSHCIER-VERMEER, W. \& PASSHIER, W.F. 2000. Noise exposure and public health. Environmental Health Perspectives, 18(1):123-132.

SCHRIRE, R.A. 1990. Critical choices for South Africa: an agenda for the 1990s. London: Oxford University Press.

SIMON, D. 2001. Equitable and sustainable urban futures in post-apartheid Southern Africa. In: DE WET, C.J. \& FOX, R.C. (eds) Transforming settlement in southern Africa. Edinburgh: University Press.

SCHENCK, C.J. 2008. Report on the Sunnyside awareness walk: Tutorial Letter 101 of 2008 for Module SCK305B/WFS305Q. Pretoria: Unisa.

SCHENCK, R. 2009a. The socio-economic realities of the social work students of the University of South Africa. Social Work/Maatskaplike Werk, 45(3):299-313.

SCHENCK, R. 2009b. Personal interview with a professor at the Department of Social Work, Unisa, on 17 January 2009.

UNISA. 2006. 2015 Strategic plan: an agenda for transformation. Pretoria.

UNISA HEMIS figures for 2008. Retrieved from Unisa Information and Analysis Portal. [Online] Available: http://heda.unisa.ac.za/heda/fsMain.htm. [Accessed: 25/09/2009].

VAN DER MERWE, I.J. 1984. Die stad en sy omgewing ( $2^{\text {nd }}$ ed). Stellenbosch: University Publishers.

VISSER, H.J. 2009. Personal interview with senior specialist: information and strategic analysis from the Department of Information and Strategic Analysis (DISA), Unisa, 25 September.

WASSERMAN, S. \& FAUST, K. 1994. Social network analysis: methods and applications. London: Cambridge University Press.

WALKER, L., REID, G. \& CORNELL, M. 2004. Waiting to happen: HIV/AIDS in South Africa: the bigger picture. Cape Town: Juta \& Co.

ZIMBA, R.F. 2002. Indigenous conceptions of childhood development and social realities in southern Africa. In: KELLER, H., POORTINGA, Y.H. \& SCHÖLMERICH, A. (eds) Between culture and biology: perspectives on ontogenetic development. London: Cambridge University Press.

Dr Assim Hashim Alpaslan, Department of Social Work, University of South Africa, Pretoria, South Africa. 